Nat. Hazards Earth Syst. Sci., 18, 1315-1325, 2018

https://doi.org/10.5194/nhess-18-1315-2018

(C) Author(s) 2018. This work is distributed under

the Creative Commons Attribution 4.0 License.

\title{
Mapping individuals' earthquake preparedness in China
}

\author{
Guochun $\mathrm{Wu}^{1}$, Ziqiang $\mathrm{Han}^{2,3}$, Weijin $\mathrm{Xu}^{1}$, and Yue Gong ${ }^{4}$ \\ ${ }^{1}$ Institute of Geophysics, China Earthquake Administration, Beijing, 100081, China \\ ${ }^{2}$ Institute for Disaster Management and Reconstruction, Sichuan University, Chengdu, 610207, China \\ ${ }^{3}$ Center for Crisis Management Research, Tsinghua University, Beijing 100084, China \\ ${ }^{4}$ China Earthquake Disaster Prevention Center, Beijing, 100000, China
}

Correspondence: Ziqiang Han (hanziqiang@ scu.edu.cn)

Received: 30 October 2017 - Discussion started: 9 November 2017

Revised: 18 April 2018 - Accepted: 23 April 2018 - Published: 14 May 2018

\begin{abstract}
Disaster preparedness is critical for reducing potential impact. This paper contributes to current knowledge of disaster preparedness using representative national sample data from China, which faces high earthquake risks in many areas of the country. The adoption of earthquake preparedness activities by the general public, including five indicators of material preparedness and five indicators of awareness preparedness, were surveyed and 3245 respondents from all 31 provinces of Mainland China participated in the survey. Linear regression models and logit regression models were used to analyze the effects of potential influencing factors. Overall, the preparedness levels are not satisfied, with a material preparation score of 3.02 (1-5), and awareness preparation score of 2.79 (1-5), nationally. Meanwhile, residents from western China, which has higher earthquake risk, have higher degrees of preparedness. The concern for disaster risk reduction (DRR) and the concern for building safety and participation in public affairs are consistent positive predictors of both material and awareness preparedness. The demographic and socioeconomic variables' effects, such as gender, age, education, income, urban/rural division, and building size, vary according to different preparedness activities. Finally, the paper concludes with a discussion of the theoretical contribution and potential implementation.
\end{abstract}

\section{Introduction}

China is a country with high seismic risk. Within the last 100 years, one earthquake higher than Richter magnitude of 7.5 ( $M \geq 7.5$ in short) occurred every 5 years in China on average, and a $M \geq 8.0$ earthquake occurred about every 10 years. Though China only covers about $7 \%$ of the land area in the world, it has more than $35 \%$ of $M \geq 7$ continental earthquakes. In China, $58 \%$ of the whole land area, more than $50 \%$ of the cities and more than $70 \%$ of the urban population are located in an area with high seismic risk - in the seismic zone with VII intensity degree or above (Gao et al., 2015).

Moreover, most parts of China face the threat of earthquakes. Though most recent earthquakes occurred in the western region, the eastern area with high population intensity is not free of danger. Based on the data from China Earthquake Network Centre (CENC), there were 130 earthquakes between $M 6$ and 7, 16 quakes between $M 7$ and 8, and two earthquakes higher than $M 8$ occurred in Mainland China since 1980, and most of the $M \geq 6.0$ earthquake occurred in western China and rarely occurred in the eastern area. Yunnan, Qinghai, Sichuan, Gansu, Xizang (Tibet), and Xinjiang are prone-earthquake provinces. However, when we look back for a longer period, eastern China also had many earthquakes in history. From 1500 to 1980, there were $94 M 7$ 8 earthquakes and 15 earthquakes above $M 8$ in Mainland China. Tancheng earthquake (1698), Pinggu-Sanhe earthquake (1679), and Tangshan earthquake (1976) all occurred in northern and eastern China, which has a large population (Fig. 1). Thus, it can be concluded that seismic risk is a threat to most areas of China, and national studies covering all of China are needed.

Pre-disaster mitigation and preparedness are critical methods to reduce potential disaster impact and to increase the resilience of community (Cui et al., 2018). A prior study from the United States indicates that USD 1 of investment in pre-disaster mitigation and preparedness would reduce po- 


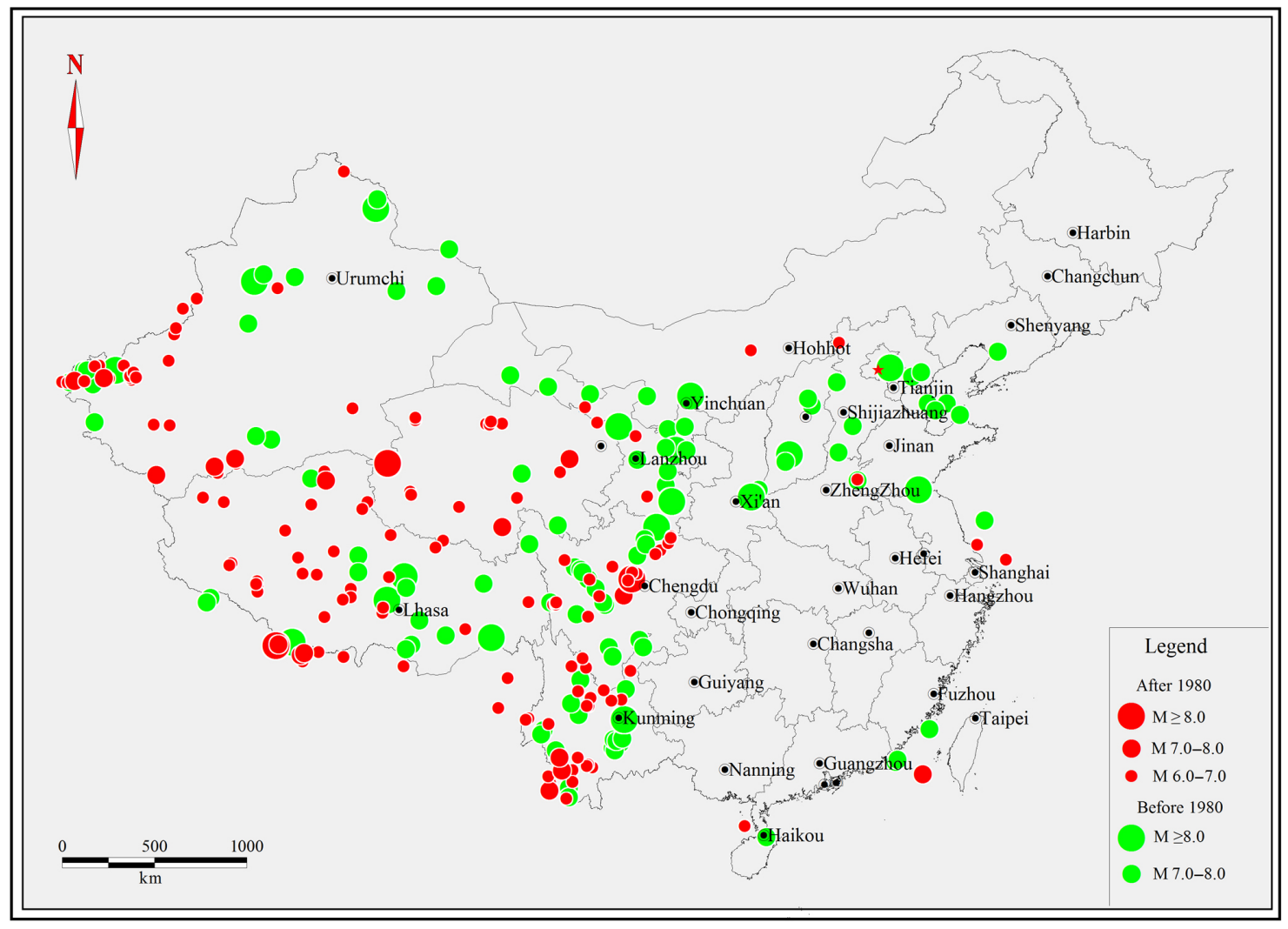

Figure 1. Historical earthquakes in mainland China and Taiwan since 1500.

tential losses by USD 4 (Godschalk et al., 2009). Thus, preparedness has become a research and practice priority in recent years. For example, a National Preparedness Strategy has been proposed in the United States, and prevention, protection, mitigation, response, and recovery are organized as the five mission areas of the core capabilities of the National Preparedness Goal (FEMA, 2015). Preparedness is clearly stated as the "shared responsibility of all individuals, families, communities, private and nonprofit sectors, faith-based organizations, and levels of governments" (FEMA, 2016). Similarly, laws and regulations in the People's Republic of China, such as the Earthquake Mitigation and Reduction Act, and the 2016-2020 National Comprehensive Disaster Risk Reduction Plan demand more efforts in mitigation and preparedness. The local government should also take responsibility for disaster preparedness education to increase the public's awareness and to improve the whole of society's disaster response capacity (The Earthquake Disaster Risk Reduction Act of the People's Republic of China, 2008; State Council of China, 2016). Therefore, studying individual preparedness for disasters can provide valuable knowledge on disaster and emergency management practices, and ultimately reduce the disaster losses.

Disaster preparedness studies have adopted various theoretical models from multiple research areas, with a con- centration in social psychology domain. The Protective Action Decision Model, Health Belief Model, Extended Parallel Process Model, Theory of Planned Behavior and Social Cognitive Theories, and Personal-Relative-To-Event Model are commonly adopted research frameworks (Duval and Mulilis, 1999; Ejeta et al., 2015; Lindell and Perry, 2012). Overall, all these models follow the psychological behavior pattern, but with different components, pathways, structures or even terminologies. Terms like protective behaviors/actions, hazards adjustment behaviors/actions, and mitigation or preparedness are common phrases used to describe the activities undertaken in anticipation of natural hazards (Bubeck et al., 2012; Kohn et al., 2012; Lindell, 2013; Lindell and Perry, 2000; Wachinger et al., 2013). In this paper, the term "preparedness" is mainly used to describe these actions undertaken to keep consistency.

The attributes of natural hazards, the features of protective actions, and the perceived characteristics of related stakeholders are the three groups of interrelated determinants of household preparedness (Lindell, 2013). The features of protective/adjustment behaviors refer to the efficacy, safety, time requirement, perceived implementation barriers and cost of undertaking that kind of preparedness action. For example, if action needs unique skills or is very costly, people will not adopt it. The stakeholder characteristics include the trust in 


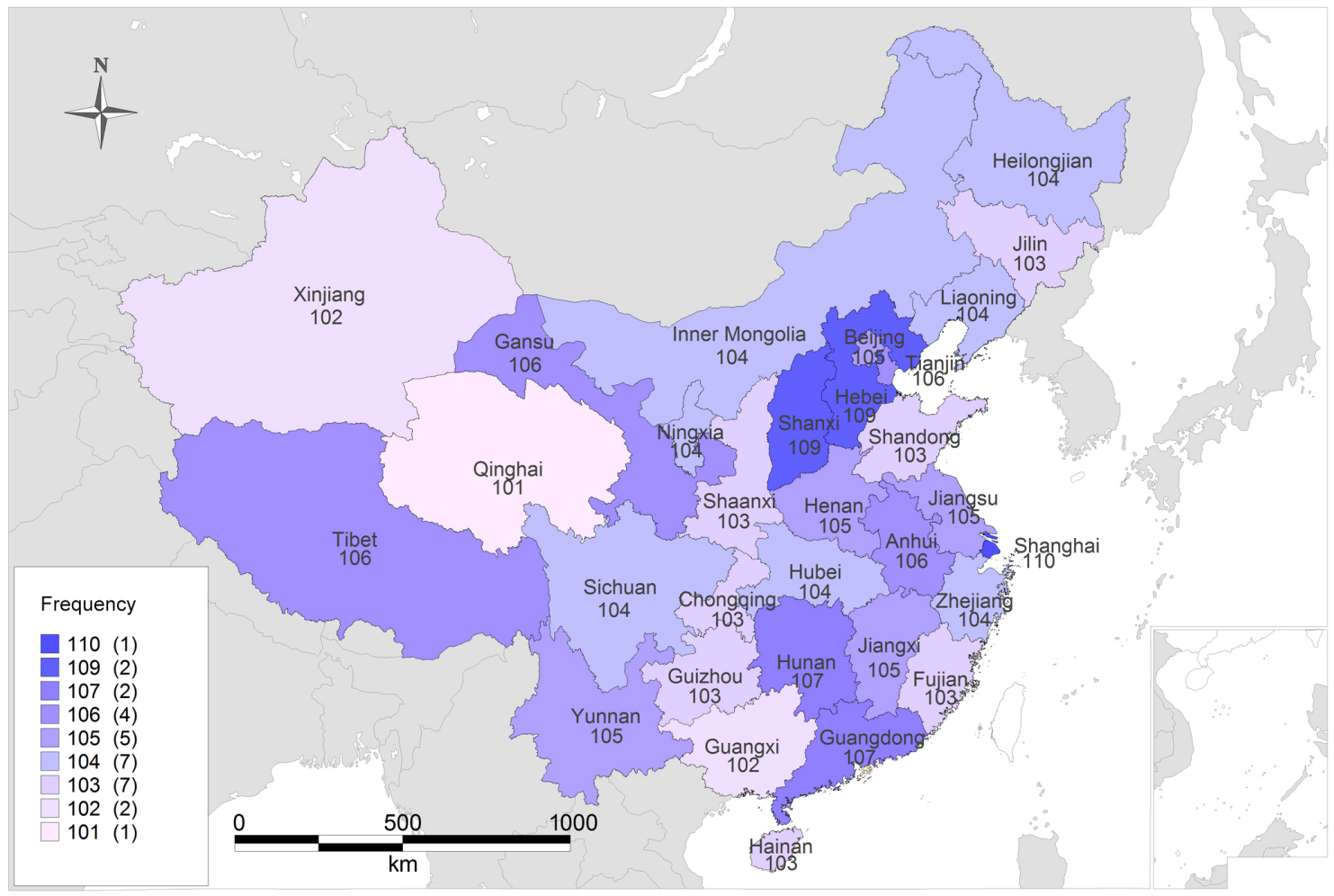

Figure 2. Sample frequency distribution by province.

varied stakeholders, feeling of responsibility, etc. If an individual believes that the government agencies should take the primary responsibility for disaster relief, that may reduce their motivation to adopt protective actions. The attributes of natural hazards cover the proximity to natural hazards, perceived risks, etc. Demographic and socioeconomic variables are always included as controlled variables in most of the studies. Recent literature reviews indicate that the relationship between risk perception and household preparedness is hardly observed in empirical studies. The factors of coping appraisal, termed as the efficacy of preparedness actions by Lindell (2013) are consistently related to preparedness behaviors (Bubeck et al., 2012; Kohn et al., 2012). Some demographic (such as gender, income, education) or household characteristics (number of dependents in a household), and previous disaster experience could also be predictors of household preparedness (Kohn et al., 2012). Overall the influencing factors of individual and household preparedness attitudes and behaviors are complex and multifaceted, and there is a need for further investigation.

For earthquake preparedness, in particular, demographic and socioeconomic variables are found to be predictors of adopting preparedness actions, though they are not consistent (Lindell et al., 2009). An exploratory study from Istanbul explored the association between earthquake preparedness and demographic variables like age, education, financial income, gender, etc., only using cross-tabulated tables, and the results showed that earthquake preparedness in this region had minor variations (Eraybar et al., 2010). Lessons learned from Turkey include the correlations between the place of residence, earthquake experience, risks, socioeconomic variables, and preparedness actions (Oral et al., 2015; Ozdemir and Yilmaz, 2011). The education level, living in a more earthquake-prone area, participated in rescue and solidarity actions previously, knowledge, and home ownership were significant predictors of preparedness in Istanbul (Tekeli-Yesil et al., 2010). Prior disaster experience and risk perception were found to be positive predictors of disaster preparedness in California (Han and Nigg, 2011), though another survey on homeowners displayed that when the appraised threat increase, only those who had sufficient resources had significant higher earthquake preparedness (Duval and Mulilis, 1999). Dhaka, Bangladesh, showed that residential unit value and individuals' education level were positively influencing factors of respondents' earthquake preparedness (Paul and Bhuiyan, 2010). Similar observations from Israel showed gender differences in earthquake risk perception and knowledge (Soffer et al., 2011). A qualitative study from New Zealand through the symbolic interactionism perspective demonstrated that how individuals make meaning of earthquake information that they are exposed to is related to their undertaking actual preparedness actions (Becker et al., 2012). Psychological factors like tendency to take risks and their locus of control, home ownership, and 
length of residence were significant predictors of earthquake preparation (Spittal et al., 2008). For earthquake proximity, the findings of Lindell and Prater (2002) in the United States demonstrated that those living in an area with high seismic hazard and those in an area of moderate seismic hazard did not show significant differences. Instead, the perception of hazard adjustment characteristics was correlated significantly with adoption intention and actual preparedness.

The association between risk perception and preparedness behaviors vary across cultures and societies (Viklund, 2003). Within the Chinese cultural context, a prior analysis revealed that people having disaster experience (heavy snow and earthquake in 2008) were not always more risk averse (Li et al., 2011). By comparing survey results from two cities with different smog exposures, Wei et al. found that proximity to threat (smog) had little impact on individuals' risk perception and protective behavior, though the participants from the two cities differ considerably in their smog experience (Wei et al., 2017). One survey of the survivors of the 2010 Yushu earthquake in China showed that individuals with a higher degree of trust in government have lower self-reported preparedness degrees (Han et al., 2017a). Studies from Taiwan indicated that prior earthquake experience affected the perceived personal impact dimension of risk perception, but not the perceived controllability (sense of efficacy of selfprotection; Kung and Chen, 2012). And households with disabled members did not have significant preparedness variations regarding natural hazards (Han et al., 2017b). Methods of risk communication may matter in encouraging individuals' adaptation of preparedness actions. Psychology experiment result demonstrated participants with higher ambiguity tolerance felt riskier and were more likely to purchase earthquake insurance when risk message came from official sources rather than peers (Zhu et al., 2012). Unlike prior studies using a small sample from specific geographical areas in China (Han et al., 2017a; Wei et al., 2017), this paper used a representative national sample, and thus it may be more precise in contributing to current studies both theoretically and practically.

By analyzing this national representative sample, we characterized individuals' earthquake preparedness in China. In detail, the central questions of concern are (1) will residents in western China (proximity to earthquake) have higher degrees of preparedness in general? (2) Would people with higher risk perceptions to an earthquake (e.g., the concern for disaster risk reduction, DRR, and the concern for building safety) have a higher degree of preparedness? (3) Is participation in public affairs associated with higher degrees of earthquake preparedness? In addition to the national representativeness of the data, we novelly explored the correlation between public involvement and the adoptions of disaster preparedness activities in China.
Table 1. Comparison of sample and national population.

\begin{tabular}{llrr}
\hline & & $\begin{array}{r}\text { Sixth NPCD } \\
(\%)\end{array}$ & $\begin{array}{r}\text { Survey result } \\
(\%)\end{array}$ \\
\hline Gender & Male & 50 & 46.4 \\
& Female & 50 & 53.6 \\
\hline \multirow{2}{*}{ Age } & Under 18 & 10 & 7 \\
& $19-29$ & 25 & 27.0 \\
& $30-39$ & 21 & 22.1 \\
& $40-49$ & 15 & 14.2 \\
& $50-59$ & 14 & 14.8 \\
& Over 60 & 15 & 14.9 \\
\hline Education & College and & 20 & 35.3 \\
& above & & \\
\hline
\end{tabular}

\section{Methods}

\subsection{Sampling}

An online survey of earthquake reduction communication was conducted from 21 September to 10 October in 2015 by a professional marketing survey company, with the sampling requirement guidelines from the authors. Gender, age, and education status were controlled in the sampling process according to the sixth national population census data (NPCD). One hundred samples in each province of Mainland China were planned to be surveyed with $5 \%$ variance. After the survey, we made a random check of respondents' URL to make sure that every respondent was unique. A total of 3245 participants from all 31 provinces in Mainland China and about 105 respondents from each province participated in the survey (Fig. 2). Our sample was consistent with the sixth NPCD regarding gender and age, with little difference of education degrees (Table 1). In our survey, $35 \%$ of the respondents had college or higher education, but in the sixth NPCD, $20 \%$ of the population had attended college.

\subsection{Measurements}

Preparedness activities: 10 preparedness activities were proposed in our survey, 5 were related to material stockpiled within a household, and the other 5 were related to capacity building and participation. The question "In order to prepare for potential earthquakes, do you have the following materials stockpiled in your home?" was used in the survey. Water, food, medicine, flashlight, and radio were proposed. If the respondent chose "yes" to that kind of material preparedness, the variable was coded as 1 . Otherwise, it was coded as 0 . Meanwhile, the aggregation of the five-material stockpile was used as a material stockpile preparedness score, and thus, it became a continuous variable ranging from 0 to 5 , indicating the increasing degree of the material stockpile. 
Additionally, we also inquired about respondents' other five preparedness-related behaviors, termed as knowledge of nearby emergency shelter, having participated in emergency exercise/drills, the intention of purchasing earthquake insurance if available, knowing the difference between earthquake prediction and earthquake warning, having visited the China Earthquake Administration Bureau's website or social media public communication page. If the respondent had positive feedback on one kind of the five activities, that variable was coded as 1 ("yes"). Otherwise, it was coded as 0 ("no"). Finally, the sum of the 10 preparedness variables ( 5 preparedness behaviors and 5 stockpiled materials) was generated as an overall degree of preparedness, ranging from 0 to 10 .

Influencing factors such as the respondents' building characteristics, socioeconomic and demographic attributes, and psychological variables were used to explore their effects on the preparedness. Meanwhile, the geographical variation at the provincial level was controlled in all the models but not reported in the tables. The building size captured the height of the buildings they occupied. It was categorized as one story, two to three stories, four to six stories, or seven on more stories. The age of the building they occupied was another variable used to measure the characteristics of the buildings, and it was a continuous variable measured in years. Gender, age, and education attainment were the demographic variables included. Gender was a dummy variable, with 1 as male. Age was a continuous variable measured in years. Education was an ordinal variable from 1 to 5 , representing Illiteracy or primary school, Middle school, High school, College, and Graduate or above. The annual income was measured by an ordinal variable ranking from 1 to 3, meaning less or equal to RMB 60000 , RMB 60000 to RMB 120000 , and greater than RMB 120000 . The ruralurban division was a dummy variable with 1 as an urban resident. We also included one measure of respondents' participation in public affairs. It was obtained by the question: "have you ever participated in your community vote?" and the answers were yes (1) or no (0). Two questions were adopted to capture respondents' risk perception. One was "do you pay attention to the disaster risk reduction knowledge or issues regularly?" and the answers were as follows: not at all (1), not a lot (2), somewhat (3), pay attention (4), and pay lots of attention (5). The others question asked was "are you concerned with your building's safety?", and the answers were yes (1) and no (0).

\subsection{Data analysis}

The 10 preparedness activities were categorized as material preparedness (water, food, medicine, flashlight, radio) and awareness preparedness (shelter knowledge, participating drill, the intention of purchasing insurance, knowing the difference between prediction and warning, seeking information from the CEA's website or social media page). We first mapped the geographical distribution of the material preparedness and awareness preparedness scores using GIS. Then, the general regression models were adopted to explore the effects of the variables on material preparedness and awareness preparedness. Lastly, we examined the correlations of these influencing variables on each kind of the preparedness activity with logistic regression models. The statistical analysis was implemented by the statistical software Stata/MP version 13.1.

\section{Results}

The 3245 respondents of our survey had an average age of 38.73 . Of the respondents, $46 \%$ were male, $61 \%$ were urban residents, $39 \%$ had participated in community vote before, $1.23 \%$ of them had primary school education attainment, $16.80 \%$ were middle school educated, $46.72 \%$ were high school educated, and $31.09 \%$ of them had attended college, and another $4.16 \%$ had graduate school education. Of them, $67.43 \%$ had an annual income less or equal than RMB $60000,22.56 \%$ of them had an annual income between RMB 60000 and RMB 120000 , and $10.01 \%$ earned more than RMB 120000 each year. Of the respondents, $11.98 \%$ were living in a building of one story, $22.53 \%$ of two to three stories, $39.14 \%$ of four to six stories, and $26.35 \%$ of seven or more stories. Of the respondents, $83 \%$ were concerned with safety of the buildings they occupied, about $68.51 \%$ of them indicated that they had paid attention to learning disaster risk reduction knowledge or skills.

In terms of preparedness, $74 \%$ of the respondents had extra water stored at home, $72 \%$ of them had extra food, $65 \%$ had medicine in preparation, $69 \%$ had a flashlight at home, and $21 \%$ of them had radio prepared. Of the respondents, $78 \%$ were aware that where was the nearest emergency shelter, $62 \%$ had participated in some kinds of emergency exercises or drills. If earthquake insurance were available, $41 \%$ of them would purchase it. Of the respondents, $45 \%$ had visited the China Earthquake Administration's website or social media (Weibo or Wechat) page for information. The aggregation of the five material-related preparedness activities was named as material preparedness in this paper, and it ranged from 0 to 5, with an average value of 3.02, with a standard deviation of 1.57. The awareness preparedness (sum of the five awareness-related actions) had a mean value of 2.79 , with a standard deviation of 1.54 (Table 2).

\subsection{Mapping the preparedness activities}

The mean values of material preparedness (5 items) and awareness preparedness ( 5 items) by province were mapped in Figs. 3 and 4. The average score of material preparedness was 3.02, while the awareness preparedness score was 2.79 , both with a range from 1 to 5. Overall, respondents in western China, which has higher earthquake risks, had higher preparedness score. Regarding material preparation, 


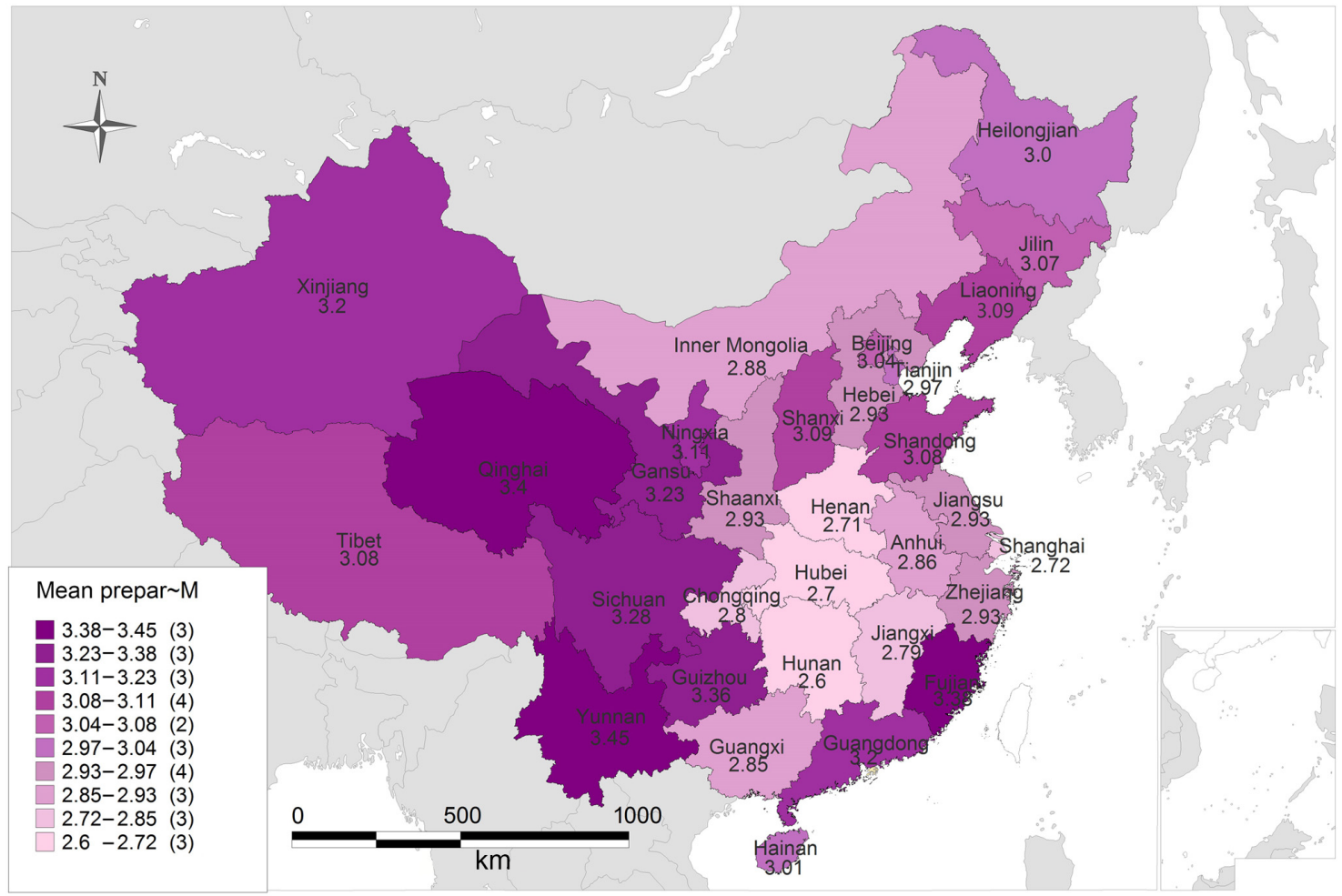

Figure 3. Mean values of material preparedness. Number of provinces in parentheses.

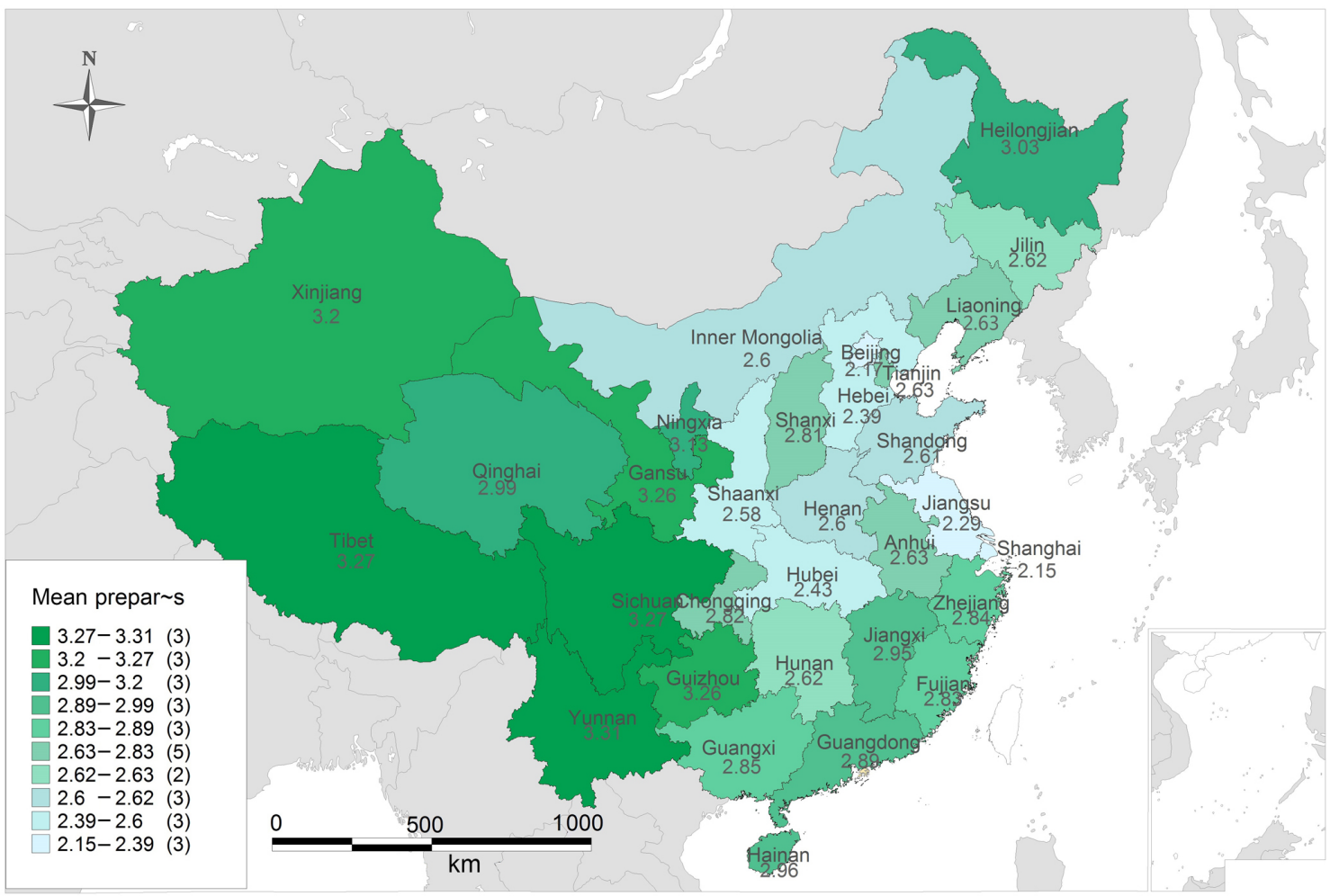

Figure 4. Mean value of awareness preparedness. Number of provinces in parentheses. 
Table 2. Descriptive analysis.

\begin{tabular}{|c|c|c|c|c|c|c|c|}
\hline Variable & Mean & SD & Min & $\operatorname{Max}$ & Variable & Frequency & Percent \\
\hline & & & & & Education & & \\
\hline Prepare awareness & 2.79 & 1.54 & 0 & 5 & Primary or lower & 40 & 1.23 \\
\hline Prepare material & 3.02 & 1.57 & 0 & 5 & Middle school & 545 & 16.80 \\
\hline Water & 0.74 & 0.44 & 0 & 1 & High school & 1516 & 46.72 \\
\hline Food & 0.72 & 0.45 & 0 & 1 & College & 1009 & 31.09 \\
\hline Medicine & 0.65 & 0.48 & 0 & 1 & Graduate or above & 135 & 4.16 \\
\hline Flashlight & 0.69 & 0.46 & 0 & 1 & $\begin{array}{l}\text { Income category (RMB) } \\
<60000\end{array}$ & 2188 & 67.43 \\
\hline Radio & 0.21 & 0.41 & 0 & 1 & $60000-120000$ & 732 & 22.56 \\
\hline Shelter & 0.78 & 0.42 & 0 & 1 & $>120000$ & 325 & 10.01 \\
\hline Drill & 0.62 & 0.49 & 0 & 1 & $\begin{array}{l}\text { Building size } \\
\text { one story }\end{array}$ & 389 & 11.98 \\
\hline Insurance & 0.41 & 0.49 & 0 & 1 & two to three stories & 731 & 22.53 \\
\hline Seek Info & 0.45 & 0.50 & 0 & 1 & four to six stories & 1270 & 39.14 \\
\hline Male & 0.46 & 0.50 & 0 & 1 & seven or more stories & 855 & 26.35 \\
\hline Age & 38.73 & 15.93 & 15 & 68 & $\begin{array}{l}\text { Concern for DRR } \\
\text { Not at all }\end{array}$ & 14 & 0.43 \\
\hline Urban & 0.61 & 0.49 & 0 & 1 & Not very concern & 146 & 4.50 \\
\hline Building Age & 11.50 & 10.85 & 0.20 & 65 & Somewhat concerned & 862 & 26.56 \\
\hline Vote & 0.39 & 0.49 & 0 & 1 & Concerned & 1514 & 46.66 \\
\hline \multirow[t]{2}{*}{$\begin{array}{l}\text { Concerned with } \\
\text { building safety }\end{array}$} & 0.83 & 0.37 & 0 & 1 & Very concerned & 709 & 21.85 \\
\hline & & & & & Total & 3245 & 100 \\
\hline
\end{tabular}

the top five provinces were Yunnan (3.45), Qinghai (3.4), Fujian (3.38), Guizhou (3.36), and Sichuan (3.28), while the three least prepared provinces were Hunan (2.6), Hubei (2.7), and Henan (2.71). For awareness preparedness, the top five prepared provinces were Yunnan (3.31), Sichuan (3.27), Xizang (3.27), Gansu (3.26), and Guizhou (3.26), while Shanghai (2.15), Beijing (2.17), Jiangsu (2.29), Hebei (2.39), and Hubei (2.43) were the five least prepared. Considering historical earthquake records in China (Fig. 1), people in western China, where there are more earthquakes, showed a higher degree of preparedness.

\subsection{Influencing factors of preparedness behaviors}

We first undertook regression analysis of the awareness preparedness score and material preparedness score using general linear regression models. The adjusted $R^{2}$ for the awareness preparedness model was 0.332 , while the adjusted $R^{2}$ for the material preparedness was 0.110 . Overall, the psychological factors and participation variables were positive predictors of preparedness. With a higher degree of concern for building safety and concern for disaster risk reduction, the respondents would have a higher degree of both awareness preparedness and material preparedness. Those who had participated in community voting also have both higher degrees of awareness and material preparedness compared with those who did not participate in the voting. Being male was also positively associated with both awareness and material preparedness. Older respondents have a lower degree of awareness preparedness, but such difference on material preparedness was not significant. Annual income was also positively correlated with awareness preparedness, but not material preparedness. It was against our expectation that urban residents had lower awareness preparedness and material preparedness degrees, though such effect on awareness preparedness was not statistically significant. The building size (height) did not affect the awareness preparedness, but people living in taller buildings would prepare more materials. The building age's effect was not significant in predicting the material preparedness but was negatively associated with awareness preparedness (Table 3).

The impact of the proposed predictors on each kind of material preparedness and awareness preparedness were estimated using logistic regression models, and the results (odds ratios) were reported in Tables 4 and 5. Overall, the concern for building safety and concern for disaster risk reduction were the two most consistent and strongest positive predictors of almost all the 10 preparedness behaviors, besides the insignificant effect of the concern for building safety or knowledge of nearby shelters. The participation variable (voting) was a strong predictors of all the five awareness preparedness actions, but its effects on most of the material pre- 
Table 3. Regression of material preparedness and awareness preparedness $(N=3245)$.

\begin{tabular}{lrr}
\hline & $\begin{array}{r}\text { Awareness } \\
\text { preparedness }\end{array}$ & $\begin{array}{r}\text { Material } \\
\text { preparedness }\end{array}$ \\
\hline Male & $0.13^{* *}(0.05)$ & $0.12^{*}(0.05)$ \\
Age & $-0.02^{* * *}(0.00)$ & $-0.00(0.00)$ \\
Education & $0.01(0.04)$ & $0.09^{*}(0.04)$ \\
Income & $0.20^{* * *}(0.05)$ & $0.05(0.05)$ \\
Urban & $-0.10(0.05)$ & $-0.13^{*}(0.06)$ \\
Building size: & & \\
two to three stories & $0.02(0.08)$ & $0.13(0.10)$ \\
four to six stories & $-0.02(0.08)$ & $0.21^{*}(0.09)$ \\
seven or more stories & $0.01(0.09)$ & $0.27^{*}(0.10)$ \\
Building age & $-0.01^{* *}(0.00)$ & $-0.00(0.00)$ \\
Vote & $0.63^{* * *}(0.05)$ & $0.13^{*}(0.06)$ \\
Concern for DRR & $0.65^{* * *}(0.03)$ & $0.28^{* * *}(0.04)$ \\
Concern for building safety & $0.62^{* * *}(0.06)$ & $0.79^{* * *}(0.07)$ \\
$R^{2}$ & 0.332 & 0.110 \\
\hline
\end{tabular}

Standard errors in parentheses; ${ }^{*} p<0.05,{ }^{* *} p<0.01$, *** $p<0.001$; the geographical variations were controlled at provincial level but not reported in the table.

paredness, such as water, food, flashlight, and radio were not statistically significant. Males were significantly more likely to obtain a radio, know the nearby shelter, and tell the difference between earthquake warning and prediction. Older respondents did not demonstrate significant differences in all the five material preparing, but they have a slightly lower probability of participating in a drill, purchasing insurance, telling the difference between prediction and warning, and seeking earthquake-related information. The education was significantly and positively associated with participating a drill and preparing water and food at home. The annual income was only significantly correlated with higher probability of preparing medicine at home, purchasing insurance, and seeking earthquake-related information. The urban residents had a significantly lower probability of preparing food, water, and medicine at home compared with rural residents, and they also have a lower probability of participating emergency drills. The effects of building size and age were not significant for most of the preparedness activities.

\section{Discussion}

In this paper, we analyzed individuals' preparedness activities for the earthquake in China using a national sample. We found that the public in western China, which has higher seismic risks, do have a higher degree of preparedness, for both material preparedness and awareness preparedness. Most of the least prepared are in the eastern provinces. This indicates that most of the public is aware of the earthquake risk in their region. The results also demonstrated that hazard proximity is positively correlated with hazard (earthquake) preparedness (Bonaiuto et al., 2016; Howe, 2011; Lindell, 2013; Mishra et al., 2010; Russell et al., 1995; Zhang et al., 2010).
We separated the preparedness activities into material preparedness and awareness preparedness. Overall, our data showed that the concern for disaster risk reduction and the concern for building safety are positively associated with both material preparedness and awareness preparedness. Moreover, the correlations between the concern for disaster risk reduction and all the five physical preparedness activities and the five awareness activities are positive. The concern with building safety's positive effect is not significant for the "shelter knowledge" only. The concern for disaster risk reduction and concern for building safety can be seen as risk perception. Similar to most of the prior studies, risk perception is a positive predictor of individual disaster preparedness (Bronfman et al., 2016; Han et al., 2017b; Han and Nigg, 2011; Sadiq and Graham, 2016; Zhang et al., 2010).

The participation in public affairs (vote) is significantly and positively associated with the overall awareness preparedness score and separated awareness preparedness activities, but most correlations with individual material preparedness are not significant, though the association with the overall material preparedness score is significant. In this paper, we innovatively explored the role of public participation in individual disaster preparedness. Prior studies have demonstrated that trust in relevant stakeholders, such as trust in government could discourage individuals' preparedness (Han et al., 2017a; Terpstra, 2011), though some studies provide opposite or inconclusive evidence (Basolo et al., 2009; DeYoung et al., 2016). Moreover, when an individual feels more responsible for personal safety, they prepare more for potential hazards (Arceneaux and Stein, 2006; Mulilis and Duval, 1997; Wei et al., 2017). Our results demonstrated that individuals' participation in general public affairs could be a good predictor of individuals' disaster preparedness because disaster is a public issue that impacts both individuals and the public, and also it is a shared responsibility between individuals and society.

In sum, we significantly contribute to current disaster preparedness studies by using national data from China, exploring the role of public participation, and concern for building safety, and the concern for disaster risk reduction. The findings of this paper also have valuable implications for disaster risk reduction practice: people with higher degrees of participation in public affairs would also like to invest more in disaster preparedness. The involvement in disaster risk reduction activities cannot be separated from the involvement in other public issues. However, this paper does have at least three limitations. First, we only explored the variations of preparedness at province level, which is quite large and mixed. Future studies with more specific geographical locations which can measure the proximity to hazards are needed. Second, we did not include the efficacy (Roush and Tyson, 2012; Samaddar et al., 2014) of the preparedness activities in our analysis, and the inclusion of these factors is needed in future. Third, the preparedness at organizational and community level should be investigated as well. 
Table 4. Logistic regression on material preparedness $(N=3245)$.

\begin{tabular}{lrrrrr}
\hline & Water & Food & Medicine & Flashlight & Radio \\
\hline Male & $1.00(0.09)$ & $1.13(0.10)$ & $1.10(0.09)$ & $1.03(0.08)$ & $1.53^{* * *}(0.14)$ \\
Age & $0.99(0.00)$ & $1.00(0.00)$ & $1.00(0.00)$ & $1.00(0.00)$ & $1.00(0.00)$ \\
Education & $1.23^{* *}(0.08)$ & $1.16^{*}(0.07)$ & $1.05(0.06)$ & $1.04(0.06)$ & $1.00(0.07)$ \\
Income & $0.90(0.08)$ & $0.99(0.08)$ & $1.18^{*}(0.09)$ & $1.10(0.09)$ & $1.15(0.10)$ \\
Urban & $0.75^{* *}(0.08)$ & $0.81^{*}(0.08)$ & $0.76^{* *}(0.07)$ & $0.94(0.09)$ & $1.23(0.14)$ \\
Building size: & & & & & \\
two to three stories & $0.98(0.15)$ & $1.16(0.17)$ & $1.30(0.18)$ & $1.27(0.18)$ & $0.96(0.16)$ \\
four to six stories & $1.13(0.17)$ & $1.22(0.18)$ & $1.49^{* *}(0.20)$ & $1.33^{*}(0.18)$ & $1.02(0.17)$ \\
seven or more stories & $1.31(0.22)$ & $1.40^{*}(0.23)$ & $1.58^{* *}(0.24)$ & $1.40^{*}(0.21)$ & $0.91(0.16)$ \\
Building age & $1.00(0.00)$ & $1.00(0.00)$ & $0.99(0.00)$ & $1.00(0.00)$ & $1.01(0.00)$ \\
Vote & $1.09(0.10)$ & $1.14(0.10)$ & $1.37^{* * *}(0.12)$ & $1.05(0.09)$ & $1.12(0.10)$ \\
Concern for DRR & $1.45^{* * *}(0.08)$ & $1.37^{* * *}(0.07)$ & $1.34^{* * *}(0.07)$ & $1.34^{* * *}(0.07)$ & $1.23^{* * *}(0.07)$ \\
Concern for building safety & $2.50^{* * *}(0.27)$ & $2.16^{* * *}(0.23)$ & $2.22^{* * *}(0.23)$ & $2.15^{* * *}(0.22)$ & $1.57^{* *}(0.22)$ \\
Pseudo $R^{2}$ & 0.071 & 0.059 & 0.059 & 0.049 & 0.042 \\
\hline
\end{tabular}

Odds ratios were reported; standard errors in parentheses; ${ }^{*} p<0.05,{ }^{* *} p<0.01,{ }^{* * *} p<0.001$; the geographical variations were controlled at provincial level but not reported in the table.

Table 5. Logistic regression on awareness preparedness $(N=3245)$.

\begin{tabular}{lrrrrr}
\hline & Shelter & Drill & Insurance & Predict & Seek info \\
\hline Male & $1.32^{* *}(0.12)$ & $0.87(0.07)$ & $1.13(0.09)$ & $1.32^{* * *}(0.11)$ & $1.16(0.10)$ \\
Age & $1.00(0.00)$ & $0.96^{* * *}(0.00)$ & $0.99^{* * *}(0.00)$ & $0.98^{* * *}(0.00)$ & $0.99^{* * *}(0.00)$ \\
Education & $1.00(0.07)$ & $1.16^{*}(0.08)$ & $0.95(0.06)$ & $1.04(0.06)$ & $0.91(0.06)$ \\
Income & $1.07(0.10)$ & $1.00(0.08)$ & $1.52^{* * *}(0.12)$ & $1.13(0.09)$ & $1.42^{* * *}(0.12)$ \\
Urban & $0.87(0.09)$ & $0.66^{* * *}(0.07)$ & $1.02(0.10)$ & $1.03(0.10)$ & $0.97(0.09)$ \\
Building size: & & & & & \\
two to three stories & $0.84(0.14)$ & $1.21(0.19)$ & $0.97(0.14)$ & $1.09(0.15)$ & $1.02(0.15)$ \\
four to six stories & $0.77(0.12)$ & $0.86(0.13)$ & $1.03(0.15)$ & $1.21(0.17)$ & $1.00(0.14)$ \\
seven or more stories & $0.78(0.14)$ & $0.92(0.15)$ & $0.91(0.15)$ & $1.30(0.20)$ & $1.10(0.17)$ \\
Building age & $1.00(0.00)$ & $0.99^{*}(0.00)$ & $1.00(0.00)$ & $0.99(0.00)$ & $0.99^{* * *}(0.00)$ \\
Vote & $1.62^{* * *}(0.16)$ & $2.25^{* * *}(0.20)$ & $1.67^{* * *}(0.14)$ & $1.90^{* * *}(0.16)$ & $2.18^{* * *}(0.18)$ \\
Concern for DRR & $1.72^{* * *}(0.10)$ & $1.72^{* * *}(0.10)$ & $2.27^{* * *}(0.13)$ & $2.03^{* * *}(0.11)$ & $2.20^{* * *}(0.13)$ \\
Concern for building safety & $1.07(0.12)$ & $1.59^{* * *}(0.18)$ & $3.99^{* * *}(0.59)$ & $1.86^{* * *}(0.21)$ & $2.64^{* * *}(0.34)$ \\
Pseudo $R^{2}$ & 0.071 & 0.180 & 0.163 & 0.121 & 0.170 \\
\hline
\end{tabular}

Odds ratios were reported; standard errors in parentheses; ${ }^{*} p<0.05, * * \quad p<0.01,{ }^{* * *} p<0.001$; the geographical variations were controlled at provincial level but not reported in the table.

\section{Conclusions}

This paper maps the earthquake preparedness in Mainland China using a representative national sample, for the first time as far as we know. Ten earthquake preparedness activities are proposed, five of them are material preparation,ar and five of them are awareness preparation. Overall the preparedness degrees are not satisfactory, with a national material preparedness score of $3.02(1-5)$, and a national awareness preparedness score of 2.79 (1-5). Regarding geographical distribution, western China, which has experienced earthquakes recently, has relatively higher degrees of preparation, for both material and awareness preparedness. The concern for disaster risk reduction, the concern for building safety, and participation in public affairs (vote) are consistent posi- tive predictors of both material preparedness and awareness preparedness. The roles of gender, age, education, income, urban/rural divisions, and building characteristics vary according to different preparedness activities.

Data availability. The data and analysis code are available by contacting the corresponding author.

Competing interests. The authors declare that they have no conflict of interest. 
Acknowledgements. We thank the editors, the anonymous reviewers and the short comments providers' help in making this paper better. This paper is supported by the Special Fund of the Institute of Geophysics, China Earthquake Administration (grant no. DQJB17C09); the Social Science Research Grant of the Ministry of Education, People's Republic of China (17YJC630035); the research program of the Policy and Regulation Department of CEA (no. CEA-ZC/2-08-01/2015); and the National Natural Science Funds (no. 4151101232).

Edited by: Thomas Glade

Reviewed by: two anonymous referees

\section{References}

Arceneaux, K. and Stein, R. M.: Who is Held Responsible When Disaster Strikes? The Attribution of Responsibility for a Natural Disaster in an Urban Election, J. Urban Aff., 28, 43-53, https://doi.org/10.1111/j.0735-2166.2006.00258.x, 2006.

Basolo, V., Steinberg, L. J., Burby, R. J., Levine, J., Cruz, A. M., and Huang, C.: The effects of confidence in government and information on perceived and actual preparedness for disasters, Environ. Behav., 41, 338-364, 2009.

Becker, J. S., Paton, D., Johnston, D. M., and Ronan, K. R.: A model of household preparedness for earthquakes: how individuals make meaning of earthquake information and how this influences preparedness, Nat. Hazards, 64, 107-137, https://doi.org/10.1007/s11069-012-0238-x, 2012.

Bonaiuto, M., Alves, S., De Dominicis, S., and Petruccelli, I.: Place attachment and natural hazard risk: Research review and agenda, J. Environ. Psychol., 48, 33-53, https://doi.org/10.1016/j.jenvp.2016.07.007, 2016.

Bronfman, N. C., Cisternas, P. C., López-Vázquez, E., and Cifuentes, L. A.: Trust and risk perception of natural hazards: implications for risk preparedness in Chile, Nat. Hazards, 81, 307327, https://doi.org/10.1007/s11069-015-2080-4, 2016.

Bubeck, P., Botzen, W. J. W., and Aerts, J. C. J. H.: A Review of Risk Perceptions and Other Factors that Influence Flood Mitigation Behavior, Risk Anal., 32, 1481-1495, https://doi.org/10.1111/j.1539-6924.2011.01783.x, 2012.

Cui, K., Han, Z., and Wang, D.: Resilience of an EarthquakeStricken Rural Community in Southwest China: Correlation with Disaster Risk Reduction Efforts, Int. J. Environ. Res. Pub. He., 15, 407-421, https://doi.org/10.3390/ijerph15030407, 2018.

DeYoung, S. E., Wachtendorf, T., Farmer, A. K., and Penta, S. C.: NOAA Radios and Neighbourhood Networks: Demographic Factors for Channel Preference for Hurricane Evacuation Information, J. Conting. Crisis Man., 24, 275-285, https://doi.org/10.1111/1468-5973.12123, 2016.

Duval, T. S. and Mulilis, J.-P.: A Person-Relative-to-Event (PrE) Approach to Negative Threat Appeals and Earthquake Preparedness: A Field Study, J. Appl. Soc. Psychol., 29, 495-516, https://doi.org/10.1111/j.1559-1816.1999.tb01398.x, 1999.

Ejeta, L. T., Ardalan, A., and Paton, D.: Application of Behavioral Theories to Disaster and Emergency Health Preparedness: A Systematic Review, PLOS Curr. Disasters, 7, 1-17, 10.1371/currents.dis., 2015.
Eraybar, K., Okazaki, K., and Ilki, A.: An exploratory study on perceptions of seismic risk and mitigation in two districts of Istanbul, Disasters, 34, 71-92, https://doi.org/10.1111/j.14677717.2009.01115.x, 2010.

FEMA: 2015 National Preparedness Goal, available from: https: //www.fema.gov/media-library/assets/documents/25959 (last access: 3 July 2017), 2015.

FEMA: 2016 National Preparedness Report, FEMA, available from: https://www.fema.gov/media-library/assets/documents/ 116951 (last access: 3 July 2017), 2016.

Gao, M., Wu, G., Wu, X., and Lang, C.: The Role of the National Significant Seismic Monitoring and Protection Regions Institution: From the Perspective of the Risk- Society Theory, Earthq. Res. China, 29, 1-7, 2015.

Godschalk, D. R., Rose, A., Mittler, E., Porter, K., and West, C. T.: Estimating the value of foresight: aggregate analysis of natural hazard mitigation benefits and costs, J. Environ. Plann. Man., 52, 739-756, https://doi.org/10.1080/09640560903083715, 2009.

Han, Z. and Nigg, J.: The influences of business and decision makers' characteristics on disaster preparedness - A study on the 1989 Loma Prieta earthquake, Int. J. Disaster Risk Sci., 2, 2231, https://doi.org/10.1007/s13753-011-0017-4, 2011.

Han, Z., Lu, X., Hörhager, E. I., and Yan, J.: The effects of trust in government on earthquake survivors' risk perception and preparedness in China, Nat. Hazards, 86, 437-452, https://doi.org/10.1007/s11069-016-2699-9, 2017a.

Han, Z., Wang, H., Du, Q., and Zeng, Y.: Natural Hazards Preparedness in Taiwan: A Comparison Between Households With and Without Disabled Members, Health Secur., 15, 575-581, https://doi.org/10.1089/hs.2017.0025, 2017b.

Howe, P. D.: Hurricane preparedness as anticipatory adaptation: A case study of community businesses, Glob. Environ. Change, 21, 711-720, https://doi.org/10.1016/j.gloenvcha.2011.02.001, 2011.

Kohn, S., Eaton, J. L., Feroz, S., Bainbridge, A. A., Hoolachan, J., and Barnett, D. J.: Personal Disaster Preparedness: An Integrative Review of the Literature, Disaster Med. Public, 6, 217-231, https://doi.org/10.1001/dmp.2012.47, 2012.

Kung, Y.-W. and Chen, S.-H.: Perception of Earthquake Risk in Taiwan: Effects of Gender and Past Earthquake Experience, Risk Anal., 32, 1535-1546, 2012.

Li, J.-Z., Li, S., Wang, W.-Z., Rao, L.-L., and Liu, H.: Are people always more risk averse after disasters? Surveys after a heavy snow-hit and a major earthquake in China in 2008, Appl. Cogn. Psychol., 25, 104-111, https://doi.org/10.1002/acp.1648, 2011.

Lindell, M.: North American Cities at Risk: Household Responses to Environmental Hazards, in: Cities at Risk, edited by: Joffe, H., Rossetto, T., and Adams, J., Springer Netherlands, 109-130, 2013.

Lindell, M. K. and Perry, R. W.: Household Adjustment to Earthquake Hazard A Review of Research, Environ. Behav., 32, 461501, https://doi.org/10.1177/00139160021972621, 2000.

Lindell, M. K. and Perry, R. W.: The Protective Action Decision Model: Theoretical Modifications and Additional Evidence, Risk Anal., 32, 616-632, https://doi.org/10.1111/j.15396924.2011.01647.x, 2012.

Lindell, M. K. and Prater, C. S.: Risk Area Residents' Perceptions and Adoption of Seismic Hazard Adjustments, J. Appl. 
Soc. Psychol., 32, 2377-2392, https://doi.org/10.1111/j.15591816.2002.tb01868.x, 2002.

Lindell, M. K., Arlikatti, S., and Prater, C. S.: Why People Do What They Do to Protect Against Earthquake Risk: Perceptions of Hazard Adjustment Attributes, Risk Anal., 29, 1072-1088, 2009.

Mishra, S., Mazumdar, S., and Suar, D.: Place attachment and flood preparedness, J. Environ. Psychol., 30, 187-197, https://doi.org/10.1016/j.jenvp.2009.11.005, 2010.

Mulilis, J.-P. and Duval, T. S.: The PrE Model of Coping and Tornado Preparedness: Moderating Effects of Responsibility, J. Appl. Soc. Psychol., 27, 1750-1766, https://doi.org/10.1111/j.1559-1816.1997.tb01623.x, 1997.

Oral, M., Yenel, A., Oral, E., Aydin, N., and Tuncay, T.: Earthquake experience and preparedness in Turkey, Disaster Prev. Manag., 24, 21-37, https://doi.org/10.1108/DPM-01-2013-0008, 2015.

Ozdemir, O. and Yilmaz, C.: Factors affecting risk mitigation revisited: the case of earthquake in Turkey, J. Risk Res., 14, 17-46, 2011.

Paul, B. K. and Bhuiyan, R. H.: Urban earthquake hazard: perceived seismic risk and preparedness in Dhaka City, Bangladesh, Disasters, 34, 337-359, https://doi.org/10.1111/j.14677717.2009.01132.x, 2010.

Roush, R. E. and Tyson, S. K.: Geriatric Emergency Preparedness and Response Workshops: An Evaluation of Knowledge, Attitudes, Intentions, and Self-Efficacy of Participants, Disaster Med. Public, 6, 385-392, https://doi.org/10.1001/dmp.2012.63, 2012.

Russell, L. A., Goltz, J. D., and Bourque, L. B.: Preparedness and Hazard Mitigation Actions before and after Two Earthquakes, Environ. Behav., 27, 744-770, https://doi.org/10.1177/0013916595276002, 1995.

Sadiq, A.-A. and Graham, J. D.: Exploring the Predictors of Organizational Preparedness for Natural Disasters, Risk Anal., 36, 1040-1053, https://doi.org/10.1111/risa.12478, 2016.

Samaddar, S., Chatterjee, R., Misra, B., and Tatano, H.: Outcomeexpectancy and self-efficacy: Reasons or results of flood preparedness intention?, Int. J. Disast. Risk Re., 8, 91-99, https://doi.org/10.1016/j.ijdrr.2014.02.002, 2014.

Soffer, Y., Goldberg, A., Adini, B., Cohen, R., Ben-Ezra, M., Palgi, Y., Essar, N., and Bar-Dayan, Y.: The relationship between demographic/educational parameters and perceptions, knowledge and earthquake mitigation in Israel, Disasters, 35, 36-44, https://doi.org/10.1111/j.1467-7717.2010.01191.x, 2011.
Spittal, M. J., McClure, J., Siegert, R. J., and Walkey, F. H.: Predictors of Two Types of Earthquake Preparation Survival Activities and Mitigation Activities, Environ. Behav., 40, 798-817, 2008.

State Council of China: National Comprehensive Disaster Risk Reduction Plan (2016-2020), available at: http://www.gov.cn/ zhengce/content/2017-01/13/content_5159459.htm (last access: 27 October 2017), 2016.

Tekeli-Yesil, S., Dedeoglu, N., Braun-Fahrlaender, C., and Tanner, M.: Factors Motivating Individuals to Take Precautionary Action for an Expected Earthquake in Istanbul, Risk Anal., 30, 11811195, 2010.

Terpstra, T.: Emotions, Trust, and Perceived Risk: Affective and Cognitive Routes to Flood Preparedness Behavior, Risk Anal., 31, 1658-1675, https://doi.org/10.1111/j.15396924.2011.01616.x, 2011.

The Earthquake Disaster Risk Reduction Act of the People's Republic of China, available at: http://www.cea.gov.cn/publish/dizhenj/ 465/527/528/20120216093821109166053/index.html (last access: 27 October 2017), 2008.

Viklund, M. J.: Trust and Risk Perception in Western Europe: A Cross-National Study, Risk Anal., 23, 727-738, https://doi.org/10.1111/1539-6924.00351, 2003.

Wachinger, G., Renn, O., Begg, C., and Kuhlicke, C.: The Risk Perception Paradox - Implications for Governance and Communication of Natural Hazards, Risk Anal., 33, 1049-1065, https://doi.org/10.1111/j.1539-6924.2012.01942.x, 2013.

Wei, J., Zhu, W., Marinova, D., and Wang, F.: Household adoption of smog protective behavior: a comparison between two Chinese cities, J. Risk Res., 20, 846-867, https://doi.org/10.1080/13669877.2015.1121904, 2017.

Zhang, Y., Hwang, S. N., and Lindell, M. K.: Hazard Proximity or Risk Perception? Evaluating Effects of Natural and Technological Hazards on Housing Values, Environ. Behav., 42, 597-624, https://doi.org/10.1177/0013916509334564, 2010.

Zhu, D., Xie, X., and Xie, J.: When do people feel more risk? The effect of ambiguity tolerance and message source on purchasing intention of earthquake insurance, J. Risk Res., 15, 951-965, 2012. 